
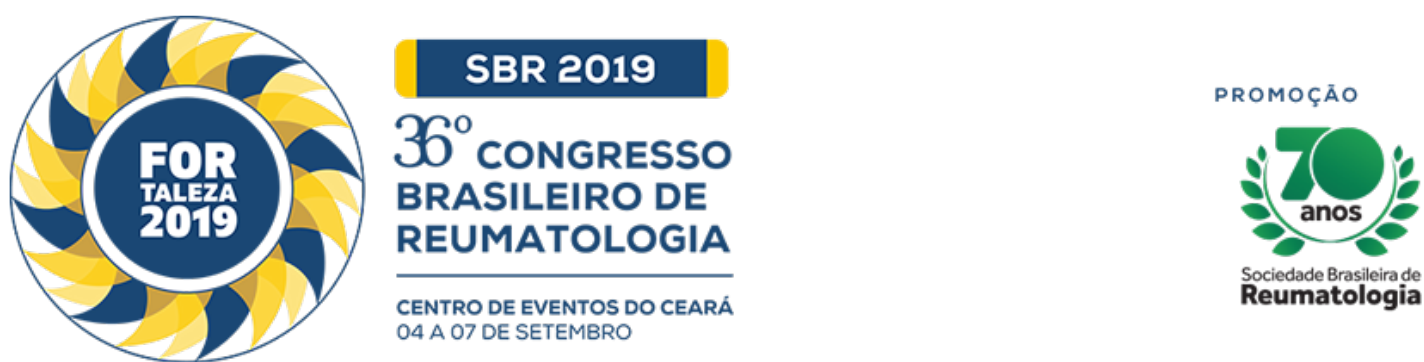

\title{
PULMONARY HYPERTENSION AS FIRST MANIFESTATION OF AUTOIMMUNE DISEASE: 2 CASE REPORTS
}

Elisa Fernandes de Melo (Universidade de Taubaté, Taubaté, SP, Brasil), Raylane Shellyda de Almeida Anate (Universidade de Taubaté, Taubaté, SP, Brasil), Vinicius Verlangieri Soubihe (Universidade de Taubaté, Taubaté, SP, Brasil), Natália Engler Ravasio (Universidade de Taubaté, Taubaté, SP, Brasil), Valéria Lima da Cruz (Universidade de Taubaté, Taubaté, SP, Brasil), Drielle Rezende Pavanitto (Universidade de Taubaté, Taubaté, SP, Brasil), Tainara Mariana Ferreira Leismann (Universidade de Taubaté, Taubaté, SP, Brasil)

\section{BACKGROUND}

Pulmonary arterial hypertension (PAH) is defined as a resting mean pulmonary arterial pressure $\geq 25$ $\mathrm{mmHg}$ or $30 \mathrm{mmHg}$ with exercise. It is complication of autoimmune diseases and is becoming a major cause of morbidity and mortality. To confirm the diagnosis it is recommended to perform a right heart catheterization. The annual incidence ranges from 5 to 15 cases per million, when associated with systemic autoimmune diseases. Concerning the therapeutic approach, it is important to treat the underlying disease and focus on a better stratification of the $\mathrm{PAH}$.

\section{CASE REPORT}

CASE 1: A 22-year-old woman presented with exercise-induced shortness of breath, syncope, dry cough, sudden-onset tachycardia, constrictive chest pain and peripheral swelling. The cardiac investigation presented with a negative stress test for myocardial ischemia and also a negative CAT scan for PE, although the transthoracic echocardiogram demonstrated a severe $\mathrm{PAH}$ and pericardial effusion. Laboratory tests showed negative inflammatory markers and autoantibodies, however a positive ANA with 1: 320 homogenous nuclear pattern with reagents nucleus and metaphase plate. Fluid restriction was initiated (up to $1000 \mathrm{ml}$ per day), anticoagulation (1 mg/kg twice-daily Enoxaparin), methylprednisolone pulse therapy followed by oral corticosteroids, Azathioprine $2 \mathrm{mg} / \mathrm{kg} / \mathrm{day}$, Hydroxychloroquine $400 \mathrm{mg} /$ day and Sildenafil $60 \mathrm{mg} /$ day. Initially the PASP estimated by transthoracic echocardiogram (TTE) was $120 \mathrm{mmHg}$ (severe PAH), which was confirmed by heart catheterization as 113 $\mathrm{mmHg}$ with a transpulmonary gradient of $45 \mathrm{mmHg}$. After 3 months of medication it settles down to 65 $\mathrm{mmHg}$.

CASE 2: A 37-year-old man presented activity-related dyspnea and unilateral painful swollen right leg. Doppler ultrasound showed extensive deep vein thrombosis in the femoropopliteal segment with a PASP of $35 \mathrm{mmHg}$ in the TTE. Laboratory tests revealed ESR 58, positive ANA with 1: 160 thin dotted nuclear pattern with reagents nucleus and metaphase plate, positive anticardiolipin IgG positive (150) and reactive lupus anticoagulant. Treatment included anticoagulation ( $1 \mathrm{mg} / \mathrm{kg}$ twice-daily Enoxaparin), followed by Warfarin and Hydroxychloroquine $400 \mathrm{mg} /$ day.

\section{CONCLUSION}

The association of PAH with systemic autoimmune diseases worsens the prognosis of the disease, increasing the mortality rate. It is the third most common cause of death in systemic lupus erythematosus. Multiple etiological factors are probably involved, such as chronic recurrent thromboembolic phenomena and pulmonary thrombosis due to the presence of antiphospholipid antibodies and possible endothelial dysfunction with abnormal vascular response. 